\title{
The effectiveness of a corporate exercise intervention programme on cardiovascular risk profile, fitness and productivity: A South African view
}

\author{
G Torres, ${ }^{1}$ BPhys Ed, Hons Phys Ed, MSc Med, PhD; J Fouche, ${ }^{2}$ BA Hons Biokinetics; \\ R Redelinghuys, ${ }^{2}$ BA Human Movement Sciences, BA Hons Biokinetics; B Brussow, ${ }^{2}$ BSc Sports Science, BA Hons Biokinetics; \\ D Cronson, ${ }^{3} \mathrm{MB}$ BCh, MBA; S Zanuso, ${ }^{4} \mathrm{PhD}$; D Constantinou, ${ }^{1} \mathrm{MB}$ BCh, BSc Med Hons, MSc Med, MPhil, FFIMS, FACSM \\ ${ }^{1}$ Centre for Exercise Science and Sports Medicine, International Federation of Sports Medicine (FIMS) Collaborating Centre of Sports Medicine, \\ School of Therapeutic Sciences, Faculty of Health Sciences, University of the Witwatersrand, Johannesburg, South Africa \\ ${ }^{2}$ Private Practice, Absa Towers West, Johannesburg, South Africa \\ ${ }^{3}$ Private Practice, Dunkeld Office Aldgate Building, Johannesburg, South Africa \\ ${ }^{4}$ Centre for Applied Biological and Exercise Sciences, Coventry University, UK
}

Corresponding author: G Torres (georgia.torres@wits.ac.za)

Background. Workplace wellness and disease-prevention programmes have been given increasing attention as a means to improve employee health and lower health costs. Health risk factors have been associated with improved work productivity. Further, health risk is reduced with improved cardiorespiratory fitness (CRF). Therefore, personal and workplace benefits may be achieved by workplace wellness programmes. Objectives. To investigate the effect of an on-site exercise-based wellness programme in a South African (SA) corporation. The impact of the programme on health risk factors, physiological parameters and corporate productivity indices was assessed.

Methods. Members joining the on-site gym facility of an SA corporation embarked on an individualised 12-week exercise programme, designed using the MyWellness Technogym Cloud platform and based on the participant's cardiovascular risk stratification. Weight, height, body mass index (BMI), blood pressure, waist circumference, CRF and muscle strength measures were assessed at the start and the end of the 12-week intervention. The number of pre- and postintervention cardiac risk factors were also applied to the Association of Health Productivity Management formula to estimate the effect of the intervention on absenteeism, presenteeism and productivity loss.

Results. The number of cardiovascular risk factors decreased in the low-, medium- and high-risk groups $(68.1 \%, 42.7 \%$ and $41 \%$, respectively). Body mass and BMI decreased significantly (mean (standard deviation (SD) $-0.3(5.0) \%$ and $-0.3(5.4) \%$, respectively). Waist circumference also decreased significantly by $2.2 \%(6.3 \%)$. Only the diastolic blood pressure component of blood pressure changed significantly $(-1.2(14.7) \%)$ and $\mathrm{VO}_{2}$ peak increased by $14.2 \%$. Upper- and lower-body strength improved by $17.9 \%$ and $20 \%$, respectively. $\mathrm{VO}_{2}$ peak, BMI and lower-body strength were the only variables that changed significantly after effect size calculations were applied. Furthermore, the predicted impact on productivity loss showed a $1.1 \%$ improvement. This was the result of a predicted reduction in absenteeism $(0.4 \%)$ and a reduction in presenteeism $(0.8 \%)$.

Conclusions. This corporate on-site exercise intervention programme positively affected the cardiovascular risk factors, biometrics, muscle strength and CRF of employees. These health outcomes decreased employee productivity loss. On-site workplace wellness programmes should be encouraged.

S Afr Med J 2020;110(10):1045-1049. https://doi.org/10.7196/SAMJ.2020.v110110.14517

Workplace wellness and disease-prevention programmes have been given increasing attention as a means to improve employee health and lower health costs. Research has shown that medical costs decrease by USD2.71 - USD6.00 for every USD1.00 invested in a workplace wellness programme..$^{[1,2]}$ Furthermore, health risk factors have been associated with improved work productivity. ${ }^{[3,4]}$ Studies have shown an improvement in cardiovascular disease (CVD) risk factors after exercise intervention. ${ }^{[-8]}$ Cardiorespiratory fitness (CRF) has been shown to be an independent risk factor for CVD and all-cause mortality. ${ }^{[9-14]} \mathrm{CRF}$ is also the risk factor that attributes the highest percentage to all-cause deaths compared with other traditional risk factors. ${ }^{[15]}$ Gupta et al. ${ }^{[16]}$ and Vigen et al. ${ }^{[17]}$ found that $\mathrm{CRF}$ is a stronger predictor of CVD mortality than other risk factors. Moreover, the association between CRF and all-cause mortality is independent of existing $\mathrm{CVD},{ }^{[18]}$ the presence of chronic disease and/or other CVD risk factors. ${ }^{[15,19,20]}$ In addition, an individual's decline in CRF level has been shown to predict the development of hypertension, hypercholesterolaemia, metabolic syndrome and midlife metabolic outcomes. ${ }^{[21,22]}$ Lee et al. ${ }^{[23]}$ found that increases in CRF level decreased all-cause and CVD mortality. In contrast, changes in percentage body fat or body weight did not affect allcause and CVD mortality. Furthermore, a single baseline measure of low fitness has been associated with CVD and non-CVD mortality across 3 decades of follow-up in men and women. ${ }^{[17]}$ Recent studies have expressed CRF in the context of survival benefit per MET: each 1-MET increase (a relatively small increment achievable by most individuals) is associated with $10-25 \%$ improvement in survival. ${ }^{[24-26]}$ Efforts to improve CRF have benefits not only for individuals, but also for corporates providing access to on-site gym facilities.

This study investigated the effect of an on-site exercise-based wellness programme in a South African (SA) corporation to determine the impact of the programme on health risk factors and 
outcomes, and whether the return on investment was similar to that reported in other countries.

\section{Methods}

The setting of the study was an SA corporation in the financial business sector. The corporation established an on-site gym facility for employees. Using a prospective intervention design, the researchers invited all new members joining the facility to participate in the study, and those who signed informed consent were recruited. All employees of any gender and aged $>18$ years were considered for inclusion. Baseline measures were recorded prior to participants embarking on an individualised 12-week exercise programme, designed using the MyWellness Technogym Cloud platform. The outcome measures were repeated at the end of the exercise intervention. Participants underwent an initial assessment, were risk stratified, provided with a training programme and monitored for the duration of the 12-week programme, followed by reassessment.

\section{Measuring tools \\ CVD risk classification}

Each employee who joined the on-site exercise facility was screened using the American College of Sports Medicine/American Heart Association (ACSM/AHA) facility screening questionnaire ${ }^{[27]}$ and was classified as low, moderate or high risk according to the ACSM risk stratification guidelines. ${ }^{[28]}$ After signing informed consent, employees with low-risk stratification were assessed by a personal trainer. Employees classified as moderate or high risk were assessed by a registered biokineticist (clinical exercise specialist).

\section{Assessment}

Stature $(\mathrm{m})$ and mass $(\mathrm{kg})$ were measured using the Detecto height meter (Detecto, USA) and Tanita scale (BF-350) (Tanita, Japan), respectively. Blood pressure $(\mathrm{mmHg})$ was measured three times in a seated position with a Rossmax International blood pressure cuff (Rossmax, Taiwan), using a standardised method. The average of the two closest measures was used. Waist circumference $(\mathrm{cm})$ was measured at the greatest abdominal circumference between the lowest rib and the iliac crests.

CRF was measured using the Technogym (TG) submaximal test on a TG treadmill or cycle, depending on the participant's preferred mode of training. The TG test is a submaximal test that estimates maximal oxygen consumption $\left(\mathrm{VO}_{2} \max \right)$ using the linear relationship between heart rate and $\mathrm{VO}_{2}$ max, without subjecting the individual to high levels of physical stress. During the TG submaximal exercise testing, predetermined workloads are used to elicit a steady state of exertion (plateau in heart rate and $\mathrm{VO}_{2}$ ). The steady state heart rate at each workload is then calculated and extrapolated to the $\mathrm{VO}_{2}$ at the age-predicted maximal heart rate. This is a double-stage submaximal test and its validity and reliability have been documented $(r=0.75) .{ }^{[29]}$

Muscle strength was measured using the 10 repetition maximum method. ${ }^{[30]}$ Two tests were used, i.e. an upper-limb push movement on a chest press machine and a lower-limb push movement on a leg press machine. The predicted 1 repetition maximum (1 RM) was calculated from the heaviest load that could be pushed 10 times, using the Brzycki formula. ${ }^{[31]}$

\section{Exercise prescription}

The exercise programme was designed for and assigned to an individual using the MyWellness TG Cloud platform. The platform allows for real-time exercise data to be collected from the exercise equipment and to be viewed by a health professional. The low- risk-stratified employees ${ }^{[28]}$ were assigned 12-week exercise programmes based on the TG aspiration model. ${ }^{[32]}$ The high-riskstratified employees were assigned programmes based on their 5 primary non-communicable diseases (NCDs) of lifestyle (CVD, hypertension, dislipidaemia, diabetes and metabolic syndrome/ obesity), using MyWellness TG Cloud technology. The FITT-VP principles (frequency, intensity, time, type, volume and progression), as described by the ACSM, ${ }^{[28]}$ were used in the exercise prescription for each NCD group. Employees were inducted into their exercise programme during a one-on-one session with a biokineticist (for high-risk-stratified employees) or with a personal trainer/fitness professional (for low-risk-stratified employees).

\section{Monitoring}

The MyWellness TG online platform made it possible to record data of all exercise sessions of employees using the TG key that is inserted into the equipment. The data from the TG key were downloaded to the TG kiosk in the facility at the end of the exercise sessions. The kiosk then transmitted the data to the server of the professional site of the MyWellness TG platform. In this manner, all exercise parameters (i.e. treadmill/cycle duration, heart rate, workload, sets and repetition of strength exercises and session kcal value) captured in the facility can be considered as verified, trusted data. The trainer would investigate the exercise data of the employee on the professional site of the MyWellness TG platform once a week and provide feedback on the prescribed $\mathrm{v}$. the actual exercise frequency and volume. The coaching application of the MyWellness TG Cloud platform allowed for communication via smartphone. Each highrisk employee had a weekly group appointment with the assigned biokineticist, during which the latter used MyWellness TG to monitor and adjust the exercise programme. This contact session was also used to motivate the employee. After the 12-week post-assessment, the trainer or biokineticist discussed the results and health outcomes with the employee.

\section{Presenteeism and absenteeism}

Presenteeism and absenteeism could not be calculated directly (corporate data were not available), and were predicted using the Association of Health Productivity Management (AHPM) formula. ${ }^{[3]}$ The formula calculates the number of employees with 1 - 9 cardiac risk factors. These numbers are then used to calculate the presenteeism and absenteeism percentage for the group. The two percentages are then used to calculate the total productivity loss percentage.

\section{Statistical analysis}

Data distribution was analysed using Shapiro-Wilk's $W$-test, and any variables found to be significantly skewed were log transformed to normality, i.e. $p>0.05$ by Shapiro-Wilk's $W$-test. Student's $t$-test for paired values obtained at weeks 0 and 12 were used to analyse the changes before and after exercise intervention. Statistical significance was set at $p<0.05$. Effect size and 95\% confidence intervals (CIs) were also calculated.

Presenteeism, defined as being present at work but working at a reduced capacity, was calculated based on the employee's number of health risk factors according to the AHPM formula. ${ }^{[3]}$

\section{Results}

Employees $(n=251)$ in a corporate environment who consented and were cleared to participate in a workplace wellness intervention, completed a 12-week exercise intervention programme that resulted in improvements in cardiovascular risk category and the number of cardiovascular risk factors in each risk category (Table 1). 
The number of participants with cardiac risk factors of inactivity, smoking, obesity and hypertension decreased after the intervention (Table 1).

Furthermore, body mass, body mass index (BMI), waist circumference, diastolic blood pressure, $\mathrm{VO}_{2}$ peak, and upper- and lower-body strength improved significantly over the 12 weeks (Table 2). The greatest percentage change was found in $\mathrm{VO}_{2}$ peak and upper- and lower-body strength (Table 2). However, once effect size calculations were applied, the only variables that changed significantly were $\mathrm{BMI}, \mathrm{VO}_{2}$ peak and lower-body strength (Table 2).

The predicted impact on productivity loss showed a $1.1 \%$ improvement (Table 3). This was the result of a predicted reduction in absenteeism $(0.4 \%)$ and a reduction in presenteeism $(0.8 \%)$ (Table 3).

\section{Discussion}

This study showed that a 12 -week exercise intervention programme had a significantly positive effect on the cardiovascular risk category and CVD risk factors, physiological, muscle strength and cardiovascular fitness of employees. These health outcomes decreased employee productivity loss by $1.1 \%$.

Studies have shown improvements in CVD risk factors, ${ }^{[5-8]}$ some as many as $57 \%$ of employees having changed from high risk to moderate and low risk after an exercise intervention. ${ }^{[2]}$ Our study showed a $40 \%$ change from high risk to moderate and low risk after the exercise intervention (Table 1). It should be noted that the benefit of reducing the number of cardiovascular risk factors of employees is a reduction in their cardiovascular risk. The effect of the exercise intervention has benefits in addition to those of risk reduction. Forty percent of the risk reduction associated with exercise cannot be explained by traditional risk factors. ${ }^{[33]}$

A study by Mora et al. ${ }^{[34]}$ showed that a $20 \%$ reduction in mortality attributable to cardiovascular causes was observed for every 1-MET increase in exercise capacity among women. This study also pointed out the relative weakness of ischaemic electrocardiography responses in predicting $\mathrm{CVD}$ and all-cause mortality among women, similar to that reported among men. The importance of CRF as a vital sign was also recently published in a position statement. ${ }^{[35]}$ Our data show that an exercise-based intervention can change CRF by $14.2 \%$ (Table 2 ). This translates to a reduction in CVD risk and predicted mortality. ${ }^{[9-12,16,17]}$

Our study showed a significant improvement in upper- and lower-body muscle strength. This improvement in muscle strength may have an impact on employee mortality. Roberts et al. ${ }^{[36]}$ found that resistance training $>30 \mathrm{~min} /$ week results in a $30 \%$ reduction in risk of CVD. Research data support this association between

Table 1. Risk stratification, anthropometric and physiological variables at $\mathrm{T} 1$ and $\mathrm{T} 2$ of the 12 -week exercise intervention programme

\begin{tabular}{|c|c|c|c|c|}
\hline Variables, $\boldsymbol{n}^{\dagger}$ & $n$ & T1 & $\mathrm{T} 2$ & $p$-value \\
\hline Low cardiac risk category & 251 & 149 & 186 & \\
\hline Risk factors & & 94 & 30 & \\
\hline Moderate cardiac risk category & 251 & 52 & 35 & \\
\hline Risk factors & & 117 & 67 & \\
\hline High cardiac risk category & 251 & 50 & 30 & \\
\hline Risk factors & & 134 & 79 & \\
\hline Specific risk factors & 251 & & & \\
\hline Age & & 3 & 3 & \\
\hline Family & & 29 & 29 & \\
\hline Obesity & & 99 & 82 & \\
\hline Dyslipidaemia & & 16 & 16 & \\
\hline Inactivity & & 139 & 5 & \\
\hline Hypertension & & 41 & 27 & \\
\hline Prediabetes & & 9 & 9 & \\
\hline Smoking & & 9 & 5 & \\
\hline Female & 172 & & & \\
\hline Male & 79 & & & \\
\hline Age (year), median (IQR) & 250 & $31.0(10.0)$ & & \\
\hline Body mass (kg), mean (SD) & 251 & $79.5(19.2)$ & $79(18.3)$ & $0.04^{*}$ \\
\hline BMI $\left(\mathrm{kg} / \mathrm{m}^{2}\right)$, mean $(\mathrm{SD})$ & 251 & $28.2(6.16)$ & $26.6(6.9)$ & $0.04^{*}$ \\
\hline Waist circumference $(\mathrm{cm})$, mean $(\mathrm{SD})$ & 251 & $93.7(16.3)$ & $91.5(15.4)$ & $0.0001^{*}$ \\
\hline \multicolumn{5}{|l|}{ Physiological variables } \\
\hline Systolic blood pressure (mmHg), mean (SD) & 250 & $121.3(6.16)$ & $120.9(16.2)$ & 0.65 \\
\hline Diastolic blood pressure ( $\mathrm{mmHg})$, mean (SD) & 251 & $78.9(12.9)$ & $76.8(10.7)$ & $0.003^{*}$ \\
\hline $\mathrm{VO}_{2}$ peak $(\mathrm{mL} / \mathrm{min} / \mathrm{kg})$, median (IQR) & 243 & $38.0(28.7)$ & $43.1(16.5)$ & $0.003^{*}$ \\
\hline $\begin{array}{l}\text { Upper-body strength (kg) } \\
\text { (predicted } 1 \mathrm{RM}), \text { median (IQR) }\end{array}$ & 240 & $36.0(28.0)$ & $40.0(37.6)$ & $0.0001^{*}$ \\
\hline $\begin{array}{l}\text { Lower-body strength (kg) } \\
\text { (predicted } 1 \mathrm{RM}) \text {, median (IQR) }\end{array}$ & 245 & $106.7(68.0)$ & $133(86.9)$ & $0.0001^{*}$ \\
\hline
\end{tabular}


Table 2. Percentage changes and effect size calculations

\begin{tabular}{|c|c|c|}
\hline Variables & Change, \% & Effect size $(95 \% \mathrm{CI})$ \\
\hline Body mass (kg), mean (SD) & $-0.3(5.0)$ & $-0.03(-0.20-0.15)$ \\
\hline Body mass index $\left(\mathrm{kg} / \mathrm{m}^{2}\right)$, mean (SD) & $-0.3(5.4)$ & $-0.24^{\star}(-0.42--0.07)$ \\
\hline Waist circumference $(\mathrm{cm})$, median (IQR) & $-2.2(6.3)$ & $-0.14(-0.31-0.04)$ \\
\hline Systolic blood pressure (mmHg), mean (SD) & $0.2(12.4)$ & $-0.03(-0.21-0.14)$ \\
\hline Diastolic blood pressure (mmHg), mean (SD) & $-1.2(14.7)$ & $-0.18(-0.35-0.00)$ \\
\hline $\mathrm{VO}_{2}$ peak $(\mathrm{mL} / \mathrm{min} / \mathrm{kg})$, median $(\mathrm{IQR})$ & $14.2(36.5)$ & $0.22^{*}(0.04-0.40)$ \\
\hline $\begin{array}{l}\text { Upper-body strength (kg) } \\
\text { (predicted } 1 \text { RM), median (IQR) }\end{array}$ & $17.9(37.1)$ & $0.12(-0.06-0.30)$ \\
\hline $\begin{array}{l}\text { Lower-body strength }(\mathrm{kg}) \\
\text { (predicted } 1 \mathrm{RM}) \text {, median (IQR) }\end{array}$ & $20.0(44.2)$ & $0.33^{*}(0.15-0.51)$ \\
\hline
\end{tabular}

increased muscle strength and reduced all-cause mortality ${ }^{[37]}$ and cardiometabolic health. ${ }^{[36]}$

The 12-week exercise intervention programme implemented in our study, via its effect on CVD risk factors, had a favourable impact on employee productivity loss (Table 3 ). Health risk factors have been associated with work productivity. Boles et al. ${ }^{[3]}$ showed that a higher number of risk factors were strongly associated with greater productivity loss. Loeppke et al. ${ }^{[38]}$ found that lost productivity costs (measured as a combination of presenteeism and absenteeism) are 2.3 times higher than medical and pharmacy costs. The meta-analysis of Goetzel et al. ${ }^{[39]}$ found that the overall cost of presenteeism accounted for one-fifth to three-fifths of the total USD lost to 10 conditions. A $1.9 \%$ productivity loss has been associated with every risk factor changed and a USD950 per year per risk factor change. ${ }^{[4]}$ Our results show that, in addition to the personal health benefits, financial benefits would result from the exercise intervention.

Mckenna and Coulson ${ }^{[40]}$ found that use of a workplace exercise facility improved work productivity, supporting our use of the on-site facility.

\section{Study limitations}

Study limitations include lack of a control group, lack of control of nutritional/energy input, lack of blood tests and lack of actual absenteeism and presenteeism data from the corporate. Further research should include these outcome measures.

\section{Conclusions}

A corporate on-site exercise intervention programme can positively affect the CRF, biometrics, muscle strength and cardiovascular fitness of employees. These health outcomes can in turn decrease employee productivity loss. Despite the evidence, CRF is the only major risk factor that is not accurately, routinely and regularly assessed in the clinical setting ${ }^{[41]}$ and in the workplace. The authors of this study strongly suggest that, in addition to targeting traditional cardiac risk factors as part of the primary prevention evaluation, exercise capacity (CRF) achieved on a maximal (or submaximal) graded stress test should be evaluated to fully assess a CVD prognosis. It is suggested that workplace wellness programmes regularly assess and reward employees for increasing and maintaining CRF within an optimal range. The long-term effects of improving CRF via increased physical activity should be given at least the same importance as weight loss with regard to reducing premature mortality.
Table 3. Absenteeism, presenteeism and impact on productivity loss at $\mathrm{T} 1$ and $\mathrm{T} 2$ of the 12 -week exercise intervention programme

\begin{tabular}{llll}
\hline Variables & $\boldsymbol{N}$ & T1, \% & T2, \% \\
\hline Absenteeism & 251 & 0.6 & 0.2 \\
Presenteeism & 251 & 2.5 & 1.7 \\
Impact on productivity loss & 251 & 3.1 & 2.0 \\
T1 = start; T2 = completion. & & &
\end{tabular}

\section{Declaration. None.}

Acknowledgements. We thank Penta Systems (proprietors of the research site/facility) for allowing access to their facility and data.

Author contributions. GT made substantial contributions to the conception and design of the work, and drafted the manuscript. JF, RCR, BB, DC, SZ contributed to the conception and study design. JF, RCR and BB collected and managed data for the study. DC revised the work critically. All authors are in agreement to be accountable for all aspects of the work.

Funding. None.

Conflicts of interest. None.

1. Baicker $\mathrm{K}$, Cutler D, Song Z. Workplace wellness programs can generate savings. Health Affairs 2010;29(2):304-311. https://doi.org/10.1377/hlthaff.2009.0626

2. Berry LL, Mirabito AM, Baun WB. What's the hard return on employee wellness programs? Harvard Bus Rev 2010;(Dec):104-112.

3. Boles M, Pelletier B, Lynch W. The relationship between health risks and work productivity. J Occup Boles M, Pelletier B, Lynch W. The relationship between health risks and work productivity
Environ Med 2004;46(7):737-745. https://doi.org/10.1097/01.jom.0000131830.45744.97

4. Burton WN, Chen C, Conti D, Schultz AB, Edington DW. The association between health risk change and presenteeism change. J Occup Environ Med 2006;48(3):252-263. https://doi.org/10.1097/01. jom.0000201563.18108.af

5. Cornelissen VA, Fagard RH. Effects of endurance training on blood pressure, blood pressure regulating mechanisms, and cardiovascular risk factors. Hypertension 2005;46(4):667-675. https://doi, org/10.1161/01.HYP.0000184225.05629.51

6. Liu J, Sui X, Lavie C, et al. Effects of cardiorespiratory fitness on blood pressure trajectory with aging in a cohort of healthy men. Am Coll Cardiol 2014;64(12):1245-1253. https://doi.org/10.1016/j. jacc.2014.06.1184

7. Pattyn N, Cornelissen VA, Eshghi SRT, Vanhees L. The effect of exercise on the cardiovascular risk Pattyn N, Cornelissen VA, Eshghi SRT, Vanhees L. The effect of exercise on the cardiovascular risk
factors constituting the metabolic syndrome. Sports Med 2013;43(2):121-123. https://doi.org/10.1007/ s40279-012-0003-z

8. Thompson PD, Buchner D, Pina IL. Exercise and physical activity in the prevention and treatment of athero-sclerotic cardiovascular disease. A statement from the Council on Clinical Cardiology and the Council on Nutrition, Physical Activity, and Metabolism. Circulation 2003;107:3109-3116. https://doi. org/10.1161/01.CIR.0000075572.40158.77

9. Blair SN, Harold W, Kohl HW, et al. Physical fitness and all-cause mortality. A prospective study of healthy men and women. JAMA 1989;262(17):2395-2401. https://doi.org/10.1001/ jama.1989.03430170057028

10. Church TS, LaMonte MJ, Barlow CE, Blair SN. Cardiorespiratory fitness and body mass index as predictors of cardiovascular disease mortality among men with diabetes. Arch Intern Med 2005;165:2114-2120. https://doi.org/10.1001/archinte.165.18.2114

11. Sui X, LaMonte MJ, Laditka JN, et al. Cardiorespiratory fitness and adiposity as mortality predictors in older adults. JAMA 2007;298(21):2507-2516. https://doi.org/10.1001/jama.298.21.2507

12. Kokkinos P, Myers J. Exercise and physical activity: Clinical outcomes and applications. Circulation 2010;122:1637-1648. https://doi.org/10.1161/CIRCULATIONAHA.110.948349 
13. Khan KM, Thompson AM, Blair SN, et al. Sport and exercise as contributors to the health of nations. Lancet 2012;380(9836):59-64. https://doi.org/10.1016/S0140-6736(12)60865-4

14. Swift DL, Lavie CJ, Johannsen NM. Physical activity, cardiorespiratory fitness, and exercise training in primary and secondary coronary prevention. Circulation 2013;77(2):281-292. https://doi.org/10.1253/
pritis primary and second
circj.cj-13-0007

15. Blair SN. Physical inactivity: The biggest public health problem of the 21st century. Br J Sports Med 2009;43(1):1-2.

16. Gupta S, Rohatgi A, Colby R. Cardiorespiratory fitness and classification of risk of cardiovascular disease mortality. Clinical perspective. Circulation 2011;123(13):1377-1383. https://doi.org/10.1161/ CIRCULATIONAHA. 110.00323

17. Vigen R, Ayers C, Willis B, Defina L, Berry JD. Association of cardiorespiratory fitness with total cardiovascular and non-cardiovascular mortality across 3 decades of follow-up in men and women. Circ Cardiovasc Qual Outcomes 2012;5(3):358-364. https://doi.org/10.1161/circoutcomes.111.96318

18. Franklin BA. Survival of the fittest: Evidence for high-risk and cardioprotective fitness levels. Current Sports Med Rep 2002;1(5):257-260. https://doi.org/10.1249/00149619-200210000-00001

19. Myers J, Prakash M, Froelicher V, Partington S, Atwood JE. Exercise capacity and mortality among men referred for exercise testing. N Engl J Med 2002;346(11):793-801. https://doi.org/10.1056 NEJMoa011858

20. Myers J, McAuley P, Lavie CJ, Despres JP, Arena R, Kokkinos P. Physical activity and cardiorespiratory fitness as major markers of cardiovascular risk: Their independent and interwoven importance to fitness as major markers of cardiovascular risk: Their independent and interwoven importance
health status. Prog Cardiovasc Dis 2014;57(4):306-314. https://doi.org/10.1016/j.pcad.2014.09.011

21. Lee DC, Sui X, Church TS, Lavie CJ, Jackson AS, Blair SN. Changes in fitness and fatness on the development of cardiovascular disease risk factors hypertension, metabolic syndrome, and hypercholesterolemia. J Am Coll Cardiol 2012;59(7):665-672. https://doi.org/10.1161/ CIRCULATIONAHA 111038422

22. Chow L, Eberly LE, Austin E. Fitness changes effects on mid-life metabolic outcomes. Med Sci Sports Exerc 2014;46(8):125-167. https://doi.org/10.1249/MSS.000000000000048

23. Lee DC, Sui X, Artero EG, et al. Long-term effects of changes in cardiorespiratory fitness and body mass index on all-cause and cardiovascular disease mortality in men: The Aerobics Center Longitudinal Study. Circulation 2011;124(23):2483-2490. https://doi.org/10.1161/CIRCULATIONAHA.111.038422

24. Gulati M, Pandey DK, Arnsdorf MF. Exercise capacity and the risk of death in women. The St James Take Heart Project. Circulation 2003;108(13):1554-1559. https://doi.org/10.1161/01. CIR.0000091080.57509.E9.

25. Mark DB, Lauer MS. Exercise capacity: The prognostic variable that doesn't get enough respect. Circulation 2003;108:1534-1536. https://doi.org/10.1161/01.CIR.0000094408.38603.7E

26. Myers J. Beyond ST-segment displacement: Newer diagnostic and prognostic markers from the exercise test. Am J Med Sports 2003;5:332-336.

27. Balady GJ, Chaitman B, Driscoll D, et al. AHA/ACSM joint statement: Recommendations for cardiovascular screening, staffing, and emergency policies at health/fitness facilities. Circulation 1998;97:2283-2293. https://doi.org/10.1161/01.CIR.97.22.2283
28. Pescatelo LS, Arena R, Riebe D, Thompson PD, eds. ACSM’s Guidelines for Exercise Testing and Prescription. 9th ed. Philadelphia: Wolters Kluwer, 2013

29. Cecchinelli F, Senni S, Paolo B. Physical assessment with Technogym fitness equipment. MedSport 2008:14.

30. Nascimento MA, Cyrino ES, Nakamura FY. Validation of the Brzycki equation for the estimation of 1RM. Rev Bras Med Esporte 2007;13(1):40e-42e

31. Brzycki M. Strength testing: Predicting a one-rep max from repetitions to fatigue. J Phys Educ Recreat Dance 1993;64(1):88-90. https://doi.org/10.1080/07303084.1993.10606684

32. Russo V. Technogym aspirations. https://www.youtube.com/watch? $\mathrm{v}=-\mathrm{x} 92 \mathrm{Q} y m$ OG4k (accesse 1 February 2010)

33. Mora S, Cook N, Buring JE, Ridker PM, Lee IM. Physical activity and reduced risk of cardiovascula events: Potential mediating mechanisms. Circulation 2007;116:2110-2118. https://doi.org/10.1161/ CIRCULATIONAHA.107.729939

34. Mora S, Redberg RF, Cui Y, et al. Ability of exercise testing to predict cardiovascular and all-cause death in asymptomatic women: A 20-year follow-up of the lipid research clinics prevalence study. JAMA 2003;290(12):1600-1607. https://doi.org/10.1001/jama.290.12.1600

35. Ross R, Blair SN, Arena R, et al. Importance of assessing cardiorespiratory fitness in clinical practice: A case for fitness as a clinical vital sign. Circulation 2016;134:e653-e699. https://doi.org/10.1161 CIR.0000000000000461

36. Roberts CK, Lee MM, Katiraei M, et al. Strength fitness and body weight status on markers of cardiometabolic health. Med Sci Sports Exerc 2015;47(6):1211-1218. https://doi.org/10.1249/ MSS.0000000000000526

37. Ruiz J, Sui X, Lobelo F, et al. Association between muscular strength and mortality in men: Prospective cohort study. BMJ 2008;337:a439. https://doi.org/10.1136/bmj.a439

38. Loeppke R, Taitel M, Haufle V, Parry T, Kessler RC, Jinnett K. Health and productivity as a busines strategy: A multiemployer study. J Occup Env Med 2009;51(4):411-428. https://doi.org/10.1097/ JOM.0b013e3181a39180

39. Goetzel RZ, Long SR, Osminkowski RJ, Hawkins K, Wang S, Lynch W. Health, absence, disability, and presenteeism cost estimates of certain physical and mental health conditions affecting US employers. J Occup Environ Med 2004;46(4):398-412. https://doi.org/10.1097/01.jom.0000121151.40413.bd

40. Mckenna J, Coulson J. How does exercising at work influence work productivity? A randomized crossover trial. Med Sci Sports Exerc 2005;37(5):S323.

41. Kaminsky LA, Arena R, Bekkie TM. The importance of cardiorespiratory fitness in the United States. The need for a national registry. Circulation 2013;7:127-132. https://doi.org/10.1161/ CIR.0b013e31827ee100

Accepted 15 May 2020 